\title{
Influência das secreções de células do oviduto cultivadas in vitro sobre a viabilidade de espermatozoides bovinos congelados-descongelados
}

\author{
Patrícia Valleriote, $\mathrm{MV}_{1}$, Carla Paes de Carvalho, MSc., Diego Fernando Dubeibe, \\ MSc. ${ }_{2}$, Édgar Mauricio Mogollón-Waltero, Ph.D. ${ }_{2}$, Ângelo Jose Burla-Dias*, Ph.D. ${ }_{1}$ \\ Laboratório de Reprodução e Melhoramento Genético Animal (LRMGA), Centro de Ciência e Tecnologia \\ Agropecuária (ССT), Universidade Estadual do Norte Fluminense (UENF), Campos dos Goytacazes, Brasil \\ Laboratorio de Biotecnologías de la Reproducción Animal, Facultad de Medicina Veterinaria y Zootecnia, \\ Universidad Cooperativa de Colombia (UCC), Bucaramanga, Colombia
}

Recibido: 27 de abril del 2015 Aprobado: 29 de mayo del 2015

*Autor de correspondencia: Ângelo Jose Burla-Dias. Universidade Estadual do Norte Fluminense, Darcy Ribeiro, Avenida Alberto Lamêgo, 2000 - Parque Califórnia, Campos dos Goytacazes-RJ, Brasil. Teléfono: (+55 22) 2748-6039. Correo electrónico: angeloburlauenf@gmail.com

Cómo citar este artículo: Valleriote P, Paes de Carvalho C, Dubeibe DF, Mogollón-Waltero ÉM, Burla-Dias, ÂJ. Influência das secreções de células do oviduto cultivadas in vitro sobre a viabilidade de espermatozoides bovinos congelados-descongelados. Spei Domus. 2015;11(22):37-46. doi: http://dx.doi.org/10.16925/sp.v11i22.1158

Resumo. Introdução: nos bovinos, o oviduto é fundamental nos processos de maturação, fertilização e aquisição de competências para o adequado desenvolvimento do embrião até blastocisto. Visto que as células do revestimento interno do oviduto proporcionam substâncias que afetam positivamente os espermatozoides, à medida que atravessam o trato genital da fêmea, os componentes da superfície são modificados ou removidos pelas secreções ali presentes; ditas modificações podem incluir depleção do colesterol na superfície espermática, alteração nos glicosaminoglicanos e mudanças nos íons. Metodologia: Objetivou-se avaliar a adição de meio de cultura de células de oviduto bovino sobre parâmetros espermáticos como motilidade, vigor e integridade de membrana citoplasmática. Os espermatozoides foram incubados com $164 \mu \mathrm{l}$ de Talp-sp-Uso no grupo controle ( $\left.\mathrm{T}^{\mathrm{ct}}\right) ; 161,5 \mu \mathrm{l}$ de Talp-sp-Uso, acrescido de 2,5 $\mu \mathrm{l}$ de heparina $(20 \mu \mathrm{g} / \mathrm{ml})$ no tratamento 1 ( $\left.\mathrm{T}^{\mathrm{Hep}}\right)$ e $128 \mu \mathrm{l}$ de Talp-sp uso, acrescido de $36 \mu \mathrm{l}$ de meio de cultivo com secreções de células do oviduto bovino no Tratamento $2\left(\mathrm{~T}^{\mathrm{ov}}\right)$. Foram avaliados no tempo zero (para mostrar que os meios dos tratamentos não prejudicaram os espermatozoides) e após três horas de incubação. Resultados: não foram encontradas diferenças significativas na motilidade progressiva, vigor e integridade de membrana celular entre tratamentos. Entretanto, espermatozoides cultivados com secreções de células do oviduto apresentaram maior percentagem de motilidade total às três horas de cultivo, em comparação a espermatozoides cultivados na presença de heparina. Conclusão: as secreções de células do oviduto não afetam a motilidade progressiva nem o vigor ou a integridade da membrana citoplasmática dos espermatozoides, porém prolongam a motilidade dessas células.

Palavras-chave: capacitação espermática, células do oviduto, meio condicionado. 


\title{
Influencia de las secreciones de células del oviduto cultivadas in vitro sobre la viabilidad de espermatozoides bovinos congelados-descongelados
}

Resumen. Introducción: en los bovinos, el oviduto es fundamental en los procesos de maduración, fertilización y adquisición de competencias para el adecuado desarrollo del embrión hasta blastocisto. Una vez que las células del revestimiento interno del oviduto proporcionan sustancias que afectan positivamente los espermatozoides, a medida que cruzan el trato genital de la hembra, los componentes de la superficie se modifican o remueven por las secreciones allí presentes; tales modificaciones pueden incluir depleción del colesterol en la superficie espermática, alteración en los glicosaminoglicanos y cambio en los iones. Metodología: el objetivo fue evaluar la adición de medio de cultura de células de oviduto bovino sobre parámetros espermáticos como motilidad, vigor e integridad de membrana citoplasmática. Los espermatozoides fueron incubados con $164 \mu \mathrm{l}$ de Talp-sp-Uso en el grupo de control $\left(\mathrm{T}^{\mathrm{ct}}\right)$; $161,5 \mu \mathrm{l}$ de Talp-sp-Uso, agregado de $2,5 \mu \mathrm{l}$ de heparina $(20 \mu \mathrm{g} / \mathrm{ml})$ en el tratamiento 1 ( $\mathrm{T}^{\text {нер }}$ ) y $128 \mu \mathrm{l}$ de Talp-sp-Uso, agregado de $36 \mu \mathrm{l}$ de medio de cultivo con secreciones de células del oviduto bovino en el tratamiento $2\left(\mathrm{~T}^{\mathrm{ov}}\right)$. Se evaluaron en el tiempo cero (para mostrar que los medios de los tratamientos no perjudicaron los espermatozoides) y luego de tres horas de incubación. Resultados: no se encontraron diferencias significativas en la motilidad progresiva, vigor e integridad de membrana celular entre tratamientos. Sin embargo, espermatozoides cultivados con secreciones de células del oviduto presentaron porcentaje más grande de motilidad total a las tres horas de cultivo, en contraste con los espermatozoides cultivados en la presencia de heparina. Conclusión: las secreciones de células del oviduto no afectan la motilidad progresiva ni tampoco el vigor o la integridad de la membrana citoplasmática de los espermatozoides, pero prolongan la motilidad de esas células.

Palabras clave: capacitación espermática, células del oviduto, medio condicionado.

\section{Influence of oviduct cell secretions cultured in vitro on the viability of frozen-thawed bovine sperm cells}

\begin{abstract}
Introduction: in cattle, the oviduct is essential in the process of maturation, fertilization and acquisition of competence for proper development of an embryo until the blastocyst stage. Once the cells in the internal lining of the oviduct provide substances that positively affect sperm as it crosses the female genital tract, the surface components are modified or removed by secretions present therein. Such modifications may include cholesterol depletion on sperm surface, altered glycosaminoglycans, and change in ions. Methodology: the objective was to evaluate the influence of adding cell culture medium of bovine oviduct cells on sperm parameters such as motility, vigor, and integrity of cytoplasmic membrane. The sperm cells were incubated with $164 \mu \mathrm{l}$ of Talp-sp-Uso in the control group ( $\left.\mathrm{T}^{\mathrm{ct}}\right) ; 161.5 \mu \mathrm{l}$ of Talp-sp-Uso, in addition to $2.5 \mu \mathrm{l}$ of heparin $(20 \mu \mathrm{g} / \mathrm{ml})$ in treatment 1 ( $\left.\mathrm{T}^{\text {Hep }}\right)$ and $128 \mu \mathrm{l}$ of Talp-sp-Uso, along with $36 \mu$ of culture medium with secretions of bovine oviduct cells in treatment 2 $\left(\mathrm{T}^{\mathrm{ov}}\right)$. Tests were performed at zero time (to show that the medium of treatments did not hurt the sperm cells) and after three hours of incubation. Results: no significant differences in progressive motility, vigor and integrity of cell membrane between treatments were found. However, sperm cells cultured with oviduct cell secretions showed a greater percentage of total motility after three hours of culturing, in contrast to sperm cultured in the presence of heparin. Conclusion: oviduct cell secretions do not affect progressive motility, vigor or integrity of the cytoplasmic membrane of sperm cells; however, they prolong sperm motility.
\end{abstract}

Keywords: sperm capacitation, oviduct cells, conditioned medium. 


\section{Introdução}

O oviduto de mamíferos tem papel fundamental no processo de reprodução por ser o local onde ocorre a fertilização, além de proporcionar um lugar favorável para o desenvolvimento inicial do embrião até que este seja transportado ao interior do útero. $\mathrm{O}$ microambiente produzido pela secreção das células da mucosa do oviduto atua positivamente sobre a motilidade espermática, reação acrossômica e habilidade para fertilizar o ovócito $[1,2]$.

Diferenças histológicas regionais proporcionam mudanças na composição do fluido do oviduto, as quais podem refletir diferentes funções de seus segmentos como a maturação final do ovócito no infundíbulo, a capacitação dos espermatozoides no istmo e a fertilização na ampola. Tem sido sugerido que proteínas do oviduto podem estar envolvidas na modulação da função espermática, capacidade fertilizante e desenvolvimento embrionário inicial. No entanto, o conhecimento preciso do ambiente do oviduto ainda não foi atingido, o que dificulta a plena aplicação de técnicas que melhorem o processo de fertilização em condições in vitro [3].

Os espermatozoides de mamíferos, logo após a ejaculação, não têm a capacidade de fecundar os ovócitos, mesmo apresentando motilidade e aparente normalidade morfológica. Essa capacidade é adquirida no trato genital feminino em um processo tempo-dependente, que promove mudanças fisiológicas e bioquímicas da membrana plasmática, que, por sua vez, possibilitam a fecundação [4].

Tem sido sugerido que a adição de secreções do meio de cultivo de células de oviduto bovino às células espermáticas, em sistemas de produção in vitro de embriões, poderia contribuir para melhorias na fertilização in vitro e aumentar as taxas de clivagem e a produção de blastocistos [5].

Ante o exposto, o presente trabalho tem o objetivo de avaliar a influência da adição de meio de cultura de células de oviduto bovino sobre os parâmetros físicos de motilidade, vigor e integridade de membrana citoplasmática de espermatozoides de touros congelados-descongelados. Dessa forma, poderia contribuir ao melhoramento das condições de capacitação espermática para otimizar o processo de fertilização in vitro.

\section{Referencial teórico}

Os ovidutos, também denominados de tubas uterinas ou trompas de Falópio, são órgãos do sistema reprodutor feminino de formato sinusoide, que se estendem desde a extremidade dos cornos uterinos até a proximidade dos ovários. Eles são divididos em três regiões: infundíbulo, ampola e istmo (figura 1) [6].

Há uma diversidade de eventos cronologicamente controlados que ocorrem no oviduto pouco tempo depois da cópula: estoque de espermatozoides, capacitação espermática no istmo, liberação e transporte de espermatozoides, captação dos ovócitos, maturação final dos ovócitos no infundíbulo, fertilização na ampola, desenvolvimento embrionário inicial e transporte dos embriões até o útero. Esses eventos sequenciais requerem um sistema de suporte dinâmico e bem sincronizado pelo oviduto para atingir o sucesso no processo de fertilização [4]. Várias interações estímulo-resposta (gameta-tuba, tubagameta, gameta-gameta) fazem parte de um mecanismo que controla a fisiologia do oviduto [7].

Têm sido demonstradas alterações na concentração de proteínas, colesterol e carboidratos entre as regiões do oviduto, o que pode refletir diferentes funções desses segmentos, tais como a maturação final do ovócito no infundíbulo, a capacitação no istmo e a fertilização na ampola [8].

Durante o período de ovulação, o oviduto exibe um papel ativo, em que o lúmen fornece um ambiente adequado para a fertilização e o estrato muscular se contrai ritmicamente para movimentar o ovócito. O fluido do oviduto é capaz de promover um ambiente ótimo para a maturação final do ovócito, para a fusão do ovócito com o espermatozoide e para o início do desenvolvimento embrionário, além de servir como reservatório de espermatozoides após a cópula [9-11].

O fluido do oviduto apresenta ainda um efeito direto sobre o processo de capacitação espermática, motilidade espermática e reação acrossômica, eventos necessários para a fertilização. Tem sido demostrado que o fluido de oviduto bovino obtido das fases lútea e não lútea, da região da ampola e istmo, tem diferentes efeitos sobre a motilidade, reação acrossômica e fertilidade dos espermatozoides de bovinos $[12,13]$.

Observou-se que espermatozoides pré-incubados em fluido obtido da região do istmo apresentaram 


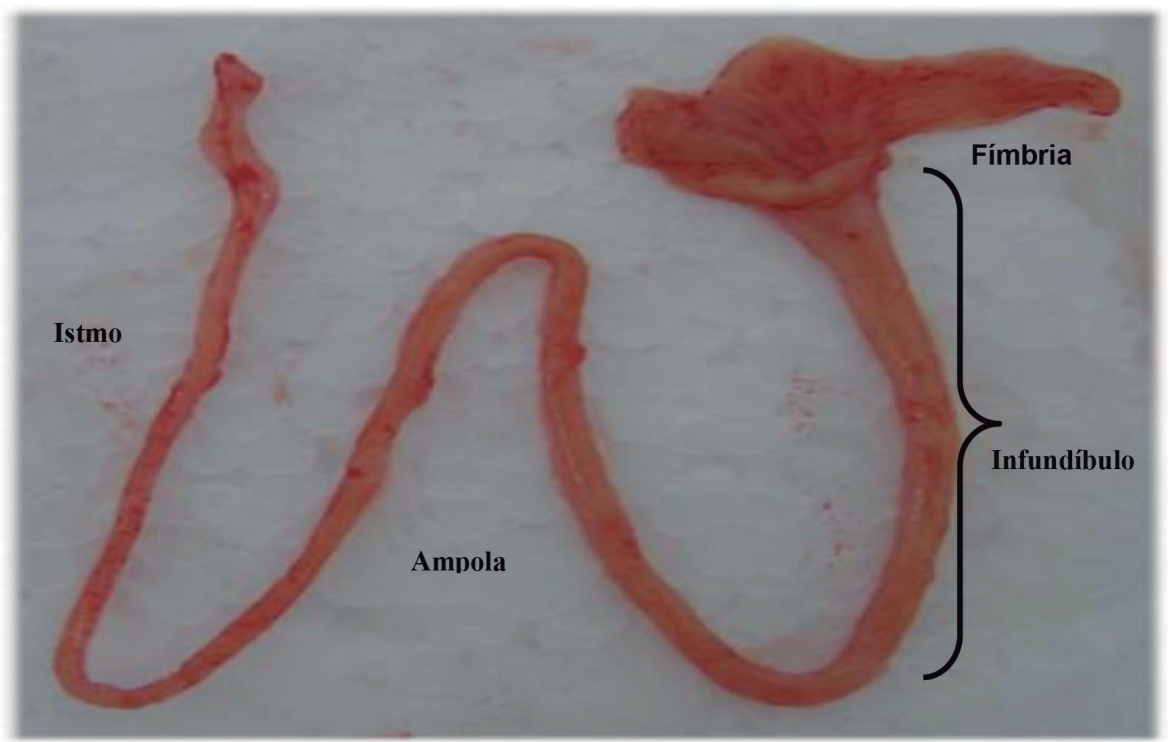

Figura 1. Oviduto bovino dissecado

Fonte: elaboração própria

maior capacidade de ligação à zona pelúcida de ovócitos do que aqueles pré-incubados em fluido da região da ampola. Entretanto, os espermatozoides incubados em fluido da ampola obtido na fase não lútea do ciclo estral resultaram em maiores taxas de fertilização do que espermatozoides pré-incubados com fluido do istmo [13].

Grippo et al. [14] verificaram que o fluido da tuba de bovinos não contém níveis fisiologicamente ativos de monossacarídeos livres (fucose, galactose, glicosamina, manose e xilose); por isso, a fucose pode ser polimerizada ou ligada a proteínas de membrana ou lipídeos das células epiteliais do oviduto [7].

As células do oviduto podem ainda participar da regulação da tensão de oxigênio e impedir, assim, os danos oxidativos, uma vez que a redução da tensão de oxigênio foi observada em meios após a cultura de células de epitélio do oviduto bovino. Além disso, enzimas antioxidantes, tais como a glutationa-peroxidase, superóxido-dismutase-Cu- $\mathrm{Zn}$ e catalase foram descritas em secreções de ovidutos de vacas ${ }^{15}$.

\section{Composição do fluido do oviduto}

O fluxo das secreções, a batida ciliar e as contrações do mesossalpinge têm um papel fundamental na formação e na mistura do líquido intraluminal do fluido do oviduto (FDo) em que os gametas se encontram. Esse FDo se origina das secreções específicas do epitélio e pelo transudado seletivo do sangue com a lâmina própria (na maior parte no segmento da ampola) que estabelece, assim, diferenças regionais na composição que pode se relacionar com o processo da preparação do gameta para a fertilização. O FDo difere do plasma sanguíneo nos termos da composição iônica, $\mathrm{pH}$, osmolaridade e índice macromolecular [10].

O FDo varia também no volume e na composição entre espécies e com o estágio do ciclo estral, sob influência hormonal [10]. O FDO dos bovinos e suínos contém também glicosaminoglicanos sulfatados (sulfato de condroitina, dermatan sulfato, queratan sulfato, heparan sulfato e heparina) ou não sulfatados (hialuronan) [16].

As proteínas encontradas no FDo estão na concentração de 10-15\% em relação à concentração encontrada no soro [17] e se dividem em dois grupos: aquelas que são sintetizadas continuamente durante o ciclo estral e as que são sintetizadas de forma cíclica e compõem a maior parte das proteínas do oviduto [18].

\section{Capacitação espermática}

A capacitação espermática está relacionada com as mudanças fisiológicas e bioquímicas da membrana plasmática dos espermatozoides para que 
ocorram interações entre estes e os ovócitos. Entre os processos envolvidos, podem-se verificar modificações na fluidez da membrana, no fluxo de íons, entre outros [19-24].

Os componentes da superfície dos espermatozoides são modificados ou removidos pelas secreções do trato genital, o que desestabiliza a bicamada fosfolipídica [25]. As modificações podem incluir depleção do colesterol na superfície espermática, alteração nos glicosaminoglicanos e mudanças nos íons à medida que os espermatozoides atravessam o trato genital [26].

A capacitação espermática leva às modificações do acrossoma necessárias para a penetração espermática da zona pelúcida [27]. A verdadeira reação do acrossoma envolve a fusão da membrana plasmática do espermatozoide com a membrana externa do acrossoma, seguida por uma extensa vesiculação sobre o segmento anterior do acrossoma. Isso difere da "falsa" reação do acrossoma, que ocorre durante a senescência ou degradação dos espermatozoides [27]. A fusão e a vesiculação do acrossoma liberam enzimas hidrolíticas, por exemplo, hialuronidase e acrosina, que estão implicadas na penetração do ovócito [26].

\section{Material e métodos}

Todos os reagentes utilizados foram da Sigma (Saint Louis, EUA), exceto aqueles especificados no texto. O trabalho foi realizado no Laboratório de Reprodução e Melhoramento Genético Animal (LRMGA) do Centro de Ciências e Tecnologias Agropecuárias (ССTA) da Universidade Estadual do Norte Fluminense Darcy Ribeiro (Uenf), em Campos dos Goytacazes, Rio de Janeiro, Brasil.

\section{Obtenção das células de oviduto}

Os ovidutos utilizados neste experimento foram obtidos de úteros provenientes de abatedouro locais, sem considerar a idade, raça, etapa do ciclo estral nem status nutricional ou clínico das vacas.
O lúmen de cada oviduto, depois de dissecado, foi lavado com 3,0 ml de tampão fosfato salina livre de cálcio (Ca2+) e magnésio ( $\mathrm{Mg} 2+)$, pH 7,2, suplementado com $5 \%$ de soro fetal bovino (sFB), $100 \mathrm{U} /$ $\mathrm{ml}$ de nistatina e $50 \mu \mathrm{g} / \mathrm{ml}$ de gentamicina.

Os ovidutos foram massageados para desprendimento das células da parede, lavados com 3,0 ml de PBS e recolhidos em tubo de centrífuga cônico, graduado, de $15 \mathrm{ml}$ para isolamento das células epiteliais por processo de decantação natural. O precipitado de células foi transferido para outro tubo de centrífuga que continha 5,0 $\mathrm{ml}$ de $\mathrm{PBS}$ para lavagem pelo mesmo sistema. Esse procedimento de lavagem foi repetido por quatro vezes para diminuir a contaminação microbiana e eliminar as células mortas. Após a última lavagem, o precipitado foi transferido para garrafas de cultivo celular de $25 \mathrm{~cm}^{2}$ que continham 5,0 $\mathrm{ml}$ de meio тсм 199 sem Hepes suplementado com $100 \mathrm{U} / \mathrm{ml}$ de nistatina, $50 \mu \mathrm{g} / \mathrm{ml}$ de gentamicina, $100 \mathrm{U} / \mathrm{ml}$ de penicilina $\mathrm{G}, 100 \mu \mathrm{g} / \mathrm{ml}$ de estreptomicina e com $10 \%$ de SFB. Foram mantidas em estufa incubadora a $5 \%$ de $\mathrm{CO}^{2}$, umidade saturada e temperatura de $38,5^{\circ} \mathrm{C}$ por um período de cinco dias.

\section{Obtenção do meio de cultivo de células do oviduto}

O meio de cultivo foi trocado nas primeiras 24 horas mantido por um período de cinco dias nos quais se observou a formação de uma monocamada de células epiteliais de oviduto bovino com 70 a $80 \%$ de confluência (figura 2). Em seguida, realizou-se a troca do meio de cultura por 5,0 $\mathrm{ml}$ de meio TCM 199 sem Hepes suplementado com $100 \mathrm{U} / \mathrm{ml}$ de nistatina, $50 \mu \mathrm{g} / \mathrm{ml}$ de gentamicina, $100 \mathrm{U} / \mathrm{ml}$ de penicilina G, $100 \mu \mathrm{g} / \mathrm{ml}$ de estreptomicina e sem SFB. As células foram mantidas nesse meio por um período de seis horas [28], a $38,5^{\circ} \mathrm{C}, 5 \%$ de $\mathrm{CO}^{2}$ e umidade saturada. Após esse tempo, o meio de cultura foi recolhido para um tubo cônico de $15 \mathrm{ml}$ e centrifugado a 700X $g$ durante 30 minutos. Posteriormente, o sobrenadante foi recolhido e congelado a $-20^{\circ} \mathrm{C}$. 


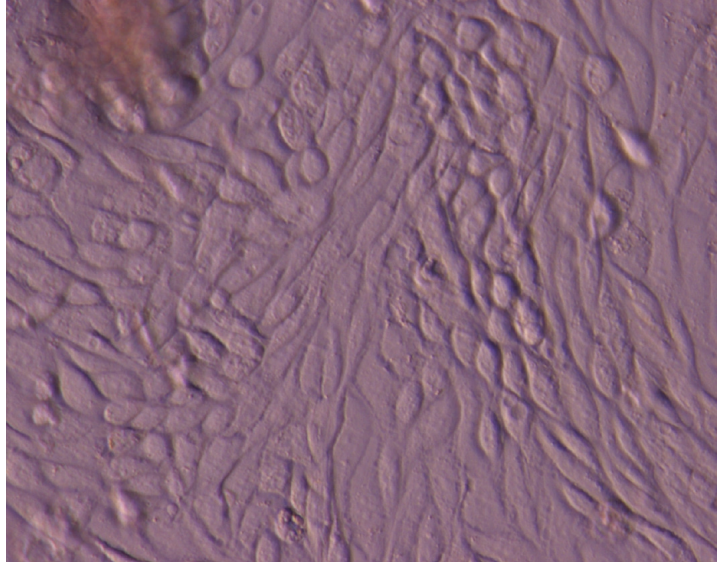

Figura 2. Cultura de células de oviduto (400X)

Fonte: elaboração própria

\section{Concentração do meio de cultivo de células de oviduto}

Inicialmente, o meio de cultivo foi centrifugado por duas vezes, a $50.000 \mathrm{X} g$ cada, em ultracentrífuga (Himac CP 75 в, HITACHI). Em seguida, o sobrenadante foi concentrado dez vezes com o concentrador proteico da AMICON utilizando uma membrana filtrante AMICON 10.000 , pressão de três bar de nitrogênio, para reter proteínas com massa molecular superior a $10 \mathrm{kDa}$. Durante todo o processo, as amostras foram mantidas em temperatura de $5^{\circ} \mathrm{C}$. Após o procedimento, o material retido na membrana foi aliquotado e armazenado a $-20^{\circ} \mathrm{C}$.

\section{Obtenção e análise do sêmen}

Foi utilizado sêmen comercial congelado de touros sexualmente maduros da raça Nelore. As palhetas de sêmen foram descongeladas em banho-maria (Temp Therm Bм. 6), a $37^{\circ} \mathrm{C}$ por 30 seg e, em seguida, avaliadas quanto à motilidade total, motilidade progressiva, vigor e integridade de membrana. Foram utilizados os padrões do Manual de Exame Andrológico do Colégio Brasileiro de Reprodução Animal (CBRA, 1998) para avaliação de sêmen congelado de touros.

\section{Seleção espermática}

A seleção espermática foi realizada pelo gradiente descontínuo de Percoll 90-45\% (figura 3); utilizou-se uma palheta de sêmen para um gradiente de $2000 \mu \mathrm{l}$.

Inicialmente, foi realizada a centrifugação a $600 \mathrm{X} g$ por oito minutos. O sobrenadante foi descartado e o precipitado ressuspenso em $5 \mathrm{ml}$ de Talp-spLavagem (meio Talp acrescido de $0,2 \mathrm{mM}$ de piruvato de sódio, $100 \mathrm{UI} / \mathrm{ml}$ de penicilina $\mathrm{G}, 100 \mu \mathrm{g} / \mathrm{ml}$ de estreptomicina e 0,01 g de PVA, previamente estabilizado por três horas em estufa incubadora a $5 \%$ de $\mathrm{CO}^{2}, 38,5^{\circ} \mathrm{C}$ e umidade saturada). Em seguida, foi realizada uma centrifugação a $150 \mathrm{X} g$ por três minutos. A fração enriquecida de espermatozoides móveis foi ressuspensa em Talp-sp-Uso (meio Talp suplementado com 0,2 $\mathrm{mM}$ de piruvato de sódio, $100 \mathrm{UI} / \mathrm{ml} \mathrm{de}$ penicilina $\mathrm{G}, 100 \mu \mathrm{g} / \mathrm{ml}$ de estreptomicina e $0,6 \%$ de BSA fração V), de modo a apresentar uma concentração final de 50×106 espermatozoides $/ \mathrm{ml}$.

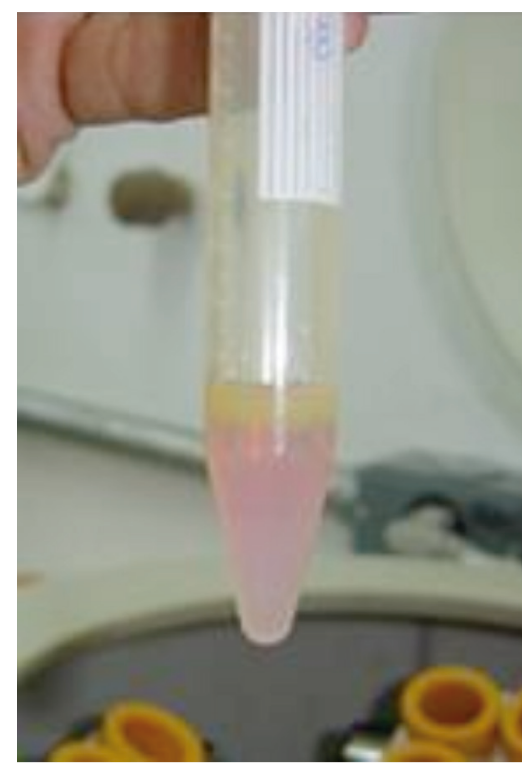

Figura 3. Gradiente de Percoll para seleção dos espermatozoides

Fonte: elaboração própria

\section{Tratamentos}

A suspensão obtida, logo após a seleção espermática, foi dividida em volumes iguais para serem incubados durante três horas a $5 \%$ de $\mathrm{CO}^{2}$, temperatura de $38,5^{\circ} \mathrm{C}$ e umidade saturada nas condições descritas abaixo. 
- Grupo Controle $\left(\mathrm{T}^{\mathrm{ct}}\right)=164 \mu \mathrm{l}$ de Talp-sp-Uso, acrescido de $36 \mu \mathrm{l}$ de suspensão espermática.

- Tratamento $1\left(\mathrm{~T}^{\text {Hep }}\right)=161,5 \mu \mathrm{l}$ de Talp-sp-Uso, acrescido de $2,5 \mu \mathrm{l}$ de heparina $(20 \mu \mathrm{g} / \mathrm{mL})$ e de $36 \mu \mathrm{l}$ de suspensão espermática. Como grupo controle com indução da capacitação espermática [29].

- Tratamento $2\left(\mathrm{~T}^{\mathrm{ov}}\right)=128 \mu \mathrm{l}$ de Talp-sp uso, acrescido de $36 \mu$ l de meio de cultivo com secreções de células do oviduto bovino e $36 \mu \mathrm{l}$ de suspensão espermática.

No tempo zero e depois de três horas de incubação, as análises dos parâmetros físicos da qualidade espermática foram realizadas na forma descrita a seguir.

\section{Avaliação da motilidade espermática}

A motilidade espermática (motilidade total e motilidade progressiva) e o vigor foram avaliados subjetivamente em microscópio óptico com objetivo de 10X a 40X, uma gota de $10 \mu \mathrm{l}$ de sêmen foi utilizada sobre uma lâmina coberta por lamínula, previamente aquecida e mantida a $37^{\circ} \mathrm{C}$ durante a avaliação. A motilidade foi a média dos valores achados por dois observadores e expressou-se em porcentagem [30].

\section{Avaliação do vigor}

O vigor avalia a velocidade do deslocamento dos espermatozoides no campo e é classificado em uma escala de zero a cinco, na qual zero significa ausência de movimento progressivo com deslocamento de cauda fraco e inexpressivo, e cinco, movimento vigoroso e veloz dos espermatozoides. O vigor espermático foi avaliado no mesmo equipamento utilizado para avaliação da motilidade.

\section{Avaliação da integridade de membrana citoplasmática}

A integridade da membrana citoplasmática dos espermatozoides foi avaliada mediante o teste hiposmótico. Para isso, uma alíquota de $10 \mu \mathrm{l}$ de espermatozoides foi adicionada a $300 \mu \mathrm{l}$ de uma solução de $100 \mathrm{mOsm}$ que continha $9 \mathrm{~g}$ de frutose e $4,9 \mathrm{~g}$ citrato de sódio/ litro e mantida por 30 minutos a temperatura de $37^{\circ} \mathrm{C}$. Para cada amostra, foi contado um total de 200 células e foram consideradas as células com cauda enrolada como as que tinham membrana plasmática íntegra
[31] e as células com cauda linear, como lesadas. A avaliação foi feita com auxílio de um microscópio de contraste de fase e os resultados expressos em percentagem de células com membrana plasmática íntegra.

\section{Análise estatística dos dados}

A análise dos dados foi realizada por análise de variância (ANOVA). Posteriormente, foi feita análise de significância pelo teste de Tukey, para comparação entre tratamentos e pelo teste -t LSD para comparações entre tempos. Todas as análises foram realizadas pelo software SISVAR 4.0 UFLA, com nível de significância de $5 \%$.

\section{Resultados e discussão}

Os valores médios de motilidade total (мт), motilidade progressiva (MP) e vigor (V) imediatamente após a seleção em gradientes de Percoll, foram de $91,4 \%, 80,7 \%$ e 4,0 , respectivamente, o que demonstra a eficiência desse método de seleção espermática visto que a motilidade total do sêmen descongelado variou de 50 a $60 \%$.

O Percoll é um gradiente de densidade para separação de células e partículas subcelulares por centrifugação que consiste de partículas de sílica coloidal cobertas com polivinilpirrolidona (PVP). O coloide tem se mostrado atóxico para um grande número de células e organelas [32].

Zúccari et al. [33] encontraram resultados semelhantes aos do presente trabalho ao observarem que a motilidade aumentou significativamente após a passagem do sêmen pelo gradiente de Percoll. Além da motilidade, observaram um aumento significativo de espermatozoides vivos, determinados pelo método de coloração com eosina-nigrosina e azul tripan-giemsa.

O tempo de incubação de três horas não alterou significativamente a motilidade progressiva e o vigor das amostras testadas; no entanto, promoveu uma redução na motilidade total das amostras de todos os tratamentos (tabela 1).

A avaliação dos parâmetros físicos seminais imediatamente após (tempo zero) e às três horas de incubação dos espermatozoides nos meios dos diferentes tratamentos está representada na tabela 1.

No tempo zero, não foram observadas diferenças entre os tratamentos para os parâmetros físicos (мт, MP e v) avaliados. As avaliações nesse 
Tabela 1. Parâmetros físicos do sêmen bovino após descongelamento e incubação sem heparina, com heparina ou com secreções de células de oviduto, à 0 e às 3 horas de cultivo

\begin{tabular}{|c|c|c|c|c|}
\hline & \multicolumn{3}{|c|}{ Tratamentos } \\
\hline & & $\mathbf{T}^{\mathrm{Ct}}$ & $\mathbf{T}^{\text {Hep }}$ & $\mathrm{T}^{\mathrm{ov}}$ \\
\hline \multirow{2}{*}{ MT } & oh & $85,0 \pm 11,2^{\mathrm{Aa}}$ & $80,0 \pm 10,4^{\mathrm{Aa}}$ & $86,4 \pm 4,8^{\mathrm{Aa}}$ \\
\hline & $3 \mathrm{~h}$ & $65,4 \pm 13,0^{\mathrm{ABb}}$ & $52,9 \pm 18,9^{\mathrm{Bb}}$ & $75,0 \pm 5,0^{\mathrm{Ab}}$ \\
\hline \multirow{2}{*}{ MP } & oh & $65,7 \pm 23,2^{\mathrm{Aa}}$ & $58,6 \pm 19,3^{\text {Аa }}$ & $69,3 \pm 13,7^{\mathrm{Aa}}$ \\
\hline & $3 \mathrm{~h}$ & $40,9 \pm 21,6^{\mathrm{Aa}}$ & $36,4 \pm 23,9^{\mathrm{Aa}}$ & $48,6 \pm 22,5^{\mathrm{Aa}}$ \\
\hline \multirow{2}{*}{$\mathbf{v}$} & oh & $4,0 \pm 0^{\mathrm{A}}$ & $4,0 \pm 0^{\mathrm{A}}$ & $4,0 \pm 0^{\mathrm{A}}$ \\
\hline & $3 h$ & $3,1 \pm 0,90^{\mathrm{A}}$ & $3,3 \pm 0,8^{A}$ & $3,4 \pm 0,8^{\mathrm{A}}$ \\
\hline
\end{tabular}

Valores indicam média $\pm \mathrm{DP}$ de sete repetições. $\mathrm{T}^{\mathrm{Ct}}=$ apenas o Talp-sp (controle); $\mathrm{T}^{\mathrm{Hep}}=$ adição de heparina $(20 \mu \mathrm{g} / \mathrm{mL}) ; \mathrm{T}^{\mathrm{Ov}}=\mathrm{adição}$ de meio de cultura de células de oviduto bovino. $\mathrm{MT}=$ motilidade total; $\mathrm{MP}=$ motilidade progressiva; $\mathrm{v}=$ vigor. Letras maiúsculas diferentes na mesma linha indicam diferença entre os tratamentos $(\mathrm{p}<0,05)$. Letras minúsculas diferentes na mesma coluna de cada avaliação indicam diferença entre os tempos $(\mathrm{p}<0,05)$.

Fonte: elaboração própria

momento tiveram como objetivo determinar os valores de MT, MP e v para serem posteriormente comparadas com as medidas tomadas às três horas de incubação, além de servirem para demonstrar que os meios dos diferentes tratamentos não impuseram efeitos prejudiciais aos espermatozoides.

As medidas dos parâmetros físicos tomadas às três horas de incubação mostraram que não houve diferença significativa de MP e v entre os diferentes tratamentos, porém os espermatozoides incubados em meio com secreções de células de oviduto apresentaram maiores percentuais de motilidade total que aqueles incubados em meio com heparina. Resultados semelhantes foram descritos por Kumaresan et al. [34] que observaram um aumento da viabilidade de espermatozoides de búfalos incubados com proteínas de oviduto. Yao et al. [35] também descreveram um aumento da motilidade de espermatozoides humanos cocultivados com células epiteliais de oviduto ou incubados com seu meio condicionado.

Esses resultados diferem daqueles descritos por Boquest et al. [36], que não observaram diferenças na percentagem de espermatozoides móveis após incubação com proteínas de meio condicionado de células de oviduto ou de extrato de fluido de oviduto.
Tal diferença pode dever-se aos diferentes tempos de incubação utilizados nos trabalhos (uma e três horas). Além disso, tem sido descrito que o fluido do oviduto afeta a função espermática dependendo da região do oviduto e do estágio do ciclo estral no qual o fluido ou as células são obtidas [12, 34].

Além da avaliação dos parâmetros físicos seminais, foi realizada a avaliação da funcionalidade da membrana plasmática dos espermatozoides submetidos aos diferentes tratamentos pelo teste hiposmótico. No tempo zero de incubação, todos os tratamentos apresentaram valores médios de células íntegras de aproximadamente $70 \%$ e não houve diferença entre eles (tabela 2).

Após três horas de incubação, as porcentagens médias de células íntegras detectadas pelo teste hiposmótico foi de aproximadamente $65 \%$ para todos os tratamentos (tabela 2).

Resultados diferentes foram descritos por Iman et al. [37], que observaram uma maior proporção de espermatozoides descongelados de búfalos com membrana plasmática íntegra, revelada pelo teste hiposmótico, no grupo incubado com proteínas de oviduto em fase não lútea $(32,6 \%)$ que no grupo controle (27,0\%). 
Tabela 2. Integridade de membrana de células espermáticas incubadas com heparina, sem heparina ou com secreções de células de oviduto, avaliada pelo teste hiposmótico à 0 e às 3 horas de cultivo

\begin{tabular}{|c|c|c|c|c|}
\hline & \multicolumn{3}{|c|}{ Tratamentos } \\
\hline & & $\mathbf{T}^{\mathrm{Ct}}$ & $\mathbf{T}^{\text {Hep }}$ & $T^{\text {ov }}$ \\
\hline \multirow{2}{*}{$\begin{array}{l}\text { Células íntegras } \\
\text { (\%) }\end{array}$} & oh & $71,93 \pm 15,94$ & $70,93 \pm 7,93$ & $66,72 \pm 20,83$ \\
\hline & $3 h$ & $64,28 \pm 8,96$ & $65,07 \pm 14,74$ & $64,43 \pm 16,33$ \\
\hline
\end{tabular}

Valores indicam média $\pm \mathrm{DP}$ de sete repetições. $\mathrm{T}^{\mathrm{Ct}}=$ apenas o Talp-sp (controle); $\mathrm{T}^{\mathrm{Hep}}=$ adição de heparina $(20 \mu \mathrm{g} / \mathrm{mL}) ; \mathrm{T}^{\mathrm{Ov}}=\mathrm{adição}$ de meio de cultura de células de oviduto bovino

Fonte: elaboração própria

\section{Conclusão}

As células espermáticas incubadas com meio condicionado de secreções de células de oviduto não sofreram alterações nos parâmetros físicos (motilidade e vigor) nem na funcionalidade da membrana plasmática (teste hiposmótico). Comparado com a heparina, as secreções de células de oviduto prolongaram a motilidade total dos espermatozoides.

\section{Referências}

[1] Areekijseree M, Veerapraditsin T. Characterization of porcine oviductal epithelial cells, cumulus cells and granulosa cells-conditioned media and their ability to induce acrosome reaction on frozen-thawed bovine spermatozoa. Micron. 2008; 39(2):160- 7 .

[2] Hunter RH. Components of oviduct physiology in eutherian mammals. Biological Reviews of the Cambridge Philosophical Society. 2012; 87(1): 244-55.

[3] Ghersevich S, Massa EY, Zumoffen C. Oviductal secretion and gamete interaction. Reproduction. 2015; 149(1):1-14.

[4] Coy P, García-Vázquez FA, Visconti PE, Avilés M. Roles of the oviduct in mammalian fertilization. Reproduction. 2012; 144(6):649-60.

[5] Pereira RJ, Tuli RK, Wallenhorst S, Holtz W. The Effect of Heparin, Caffeine and Calcium Ionophore A23187 on in vitro Induction of the Acrosome Reaction in Frozen-Thawed Bovine and Caprine Spermatozoa. Theriogenology. 2000; 54(2):185-92.

[6] Junqueira LC, Carneiro J. Histologia básica. 10ª ed. Rio de Janeiro: Editora Guanabara Koogan; 2004.

[7] Aguilar J, Reyley M. The uterine tubal fluid: secretion, composition and biological effects. Animal Reproduction. 2005; 2:91-105.
[8] Walter I, Bavdek S. Lectin binding patterns of porcine oviduct mucosa and endometrium during the oestrous cycle. Journal of Anatomy. 1997; 190:299-307.

[9] Kamaci M, Suludere Z, Irmak K, Can C, Bayhan H. Observation of isthmic epithelial cells from fallopian tubes at follicular phase by light and scanning electron microscope. Eastern Journal of Medicine. 1999; 4(2):51-3.

[10] Leese HJ, Tay JI, Reischl J, Downing SJ. Formation of Fallopian tubal fluid: role of a neglected epithelium. Reproduction. 2001; 121(3):339-46.

[11] Lapointe J, Bilodeau JF. Antioxidant defenses are modulated in the cow oviduct. Biology of Reproduction. 2003; 68(4):1157-64.

[12] Grippo AA, Way AL, Killian GJ. Effect of bovine ampullary and isthmic oviductal fluid on motility, acrosome reaction and fertility of bull spermatozoa. Journal of Reproduction and Fertility. 1995; 105(1):57-64.

[13] Killian GJ. Evidence for the role of oviduct secretions in sperm function, fertilization and embryo development. Animal Reproduction Science. 2004; 82:141-53.

[14] Grippo A, Luo Y, Rougeau B, Wyatt W. Monosaccharides are not detected in whole or isthmic bovine oviductal fluid collected throughout the estrous cycle, as analyzed by HPLC. Theriogenology. 2000; 53(3):717-26.

[15] Locatelli Y, Cognié Y, Vallet JC, Baril G, Verdier M, Poulin N, Legendre X, Mermillod, P. Successful use of oviduct epithelial cell coculture for in vitro production of viablered deer (Cervus elaphus) embryos. Theriogenology. 2005; 64(8):1729-39.

[16] Buhi WC. Characterization and biological roles of oviduct-specific, oestrogen-dependent glycoprotein. Reproduction. 2002; 123(3):355-62.

[17] Leese HJ. The formation and function of oviduct fluid. Journal of Reproduction and Fertility. 1988; 82:843-56. 
[18] Gandolfi F, Brevini JA, Richardson L, Brown CR, Moor RM. Characterization of proteins secreted by sheep oviduct epithelial cells and their function in embryonic development. Development. 1989; 106(2):303-12.

[19] Yanagimachi R. Mammalian fertilization. Em: Knobil EE, Neill JD. The Physiology of Reproduction. $2^{\text {a }}$ ed. Nova York: Raven Press; 1994. p. 189-317.

[20] Flesch FM, Gadella BM. Dynamics of the mammalian sperm plasma membrane in the process of fertilization. Biochimica et Biophysica Acta. 2000; 1469(3):197-235.

[21] Roldan ERS, Gomendio M. Morphological, functional and biochemical changes underlying the preparation and selection of fertilizing spermatozoa in vitro. Animal Reproduction Science. 1992; 28:69-78.

[22] Gordon I. Laboratory Production of Cattle Embryos. $1^{\text {a }}$ ed. Londres: CAB International. Wallingford; 1994.

[23] Pérez LJ, Valcarcel A, de Las Heras MA, Moses DF, Baldassare $H$. In vitro capacitation and induction of acrossomal exocytosis in ram spermatozoa as assessed by the chlortetracycline assay. Theriogenology. 1996;45(5):1037-46.

[24] Perez LJ, Valcárcel A, Heras MA, Baldassarre H. Comparative study of four techniques for evaluation of sperm quality in ovine and bovine frozen thawed samples. Reproduction in Domestic Animal. 1997;32:157-60.

[25] Suarez SS. Regulation of sperm storage and movement in the mammalian oviduct. Int J Dev Biol. 2008; 52(5-6):455-62.

[26] Hafez ESE. Reprodução Animal. 7ª ed. São Paulo: Ed. Manole Ltda; 2004.

[27] Buffone MG, Hirohashi N, Gerton GL. Unresolved Questions Concerning Mammalian Sperm Acrosomal Exocytosis. Biology of Reproduction. 2014; 90(5):112,1-8.

[28] Quintero I, Ghersevich S, Caille A, Munuce M, Daniele S, Morisol, L. Effects of human oviductal in vitro secretion on spermatozoa and search of spermoviductal proteins interactions. International Journal of Andrology. 2005;28(3):137-43.
[29] Parrish JJ. Bovine in vitro fertilization: in vitro oocyte maturation and sperm capacitation with heparin. Theriogenology. 2014;81(1):67-73.

[30] Valleriote OS, Dias AJB, Paes de Carvalho F, Paes Sobrinho C. Criopreservação de sêmen ovino em solução de trealose. Acta Scientiae Veterinariae. 2005; 33 (Supl.1):310.

[31] Correa JR, Pace MM, Zavos PM. Relationships among frozen-thawed sperm characteristics assessed via the routine semen analysis, sperm functional test and fertility of bulls in an artificial insemination program. Theriogenology. 1997;48:721-31.

[32] Pertoft H, Laurent TC, Laas T, Kagedal L. Density gradients prepared from colloidal silica particles coated by polyvinylpyrrolidone (Percoll). Analytical Biochemistry. 1978;88(1):271-82.

[33] Zúccari CE; Carrijo PR, Leite PA, Scaldelai PR, Rodovalho NC, Zanenga CA, Kiefer C, Costa e Silva E. Seleção em gradiente de Percoll ${ }^{\circledast}$ sobre os parâmetros espermáticos do sêmen bovino congelado. Rev. Bras. Saúde Prod. An. 2008;9(2):358-66.

[34] Kumaresan A, Ansari MR, Garg A. Modulation of postthaw sperm functions with oviductal proteins in buffaloes. Animal Reproduction Science. 2005; 90(1-2):73-84.

[35] Yao YQ, Ho PC, Yeung WS. Human oviductal cells produce a factor(s) that maintains the motility of human spermatozoa in vitro. Fertility and Sterility. 2000;73(3):479-86.

[36] Boquest AC, Smith JF, Briggs RM, Duganzich DM, Summers PM. Effects of bovine oviductal proteins on bull spermatozoal function. Theriogenology. 1999;51(3):583-95.

[37] Imam S, Ansari MR, Kumar A, Singh C, Bharti VK, Kumaresan A. Effect of Oviductal Proteins on Structural and Functional Characteristics of Cryopreserved Sperm in Murrah Buffaloes. Reprod. Dom. Anim. 2010;45(2):302-6. 